\title{
O QUE É IMPORTANTE PARA UMA INTERPRETAÇÃO SIMULTÂNEA EM LÍNGUA DE SINAIS NO CONTEXTO ARTÍSTICO?
}

\author{
WHAT IS IMPORTANT FOR SIMULTANEOUS INTERPRETATION OF SIGN \\ LANGUAGE IN AN ARTISTIC CONTEXT?
}

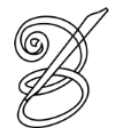 \\ Márcia Dilma FELÍCIO ${ }^{1}$ \\ Doutoranda em Estudos da Tradução (PGET/UFSC) \\ Florianópolis, Santa Catarina, Brasil \\ marciadfelicio@gmail.com
}

\begin{abstract}
Resumo: Esse artigo avalia quais elementos um público não fluente em língua de sinais considera prescindíveis para interpretação simultânea (IS) de uma narrativa em língua de sinais. Os contos em língua de sinais são performances visuais que constituem uma rede complexa de informações linguísticas e semióticas, gestos e expressões corporais. Analisamos, neste trabalho, as percepções de alunos do curso técnico de tradução e interpretação do IFSC - Campus Palhoça Bilíngue sobre dois tipos de interpretação simultânea (a primeira com muitas informações linguísticas, a segunda com poucas informações linguísticas) de um conto tecido em LIBRAS, intitulado "Sinais no metrô". O tradutor-intérprete é um mediador cultural e tem em sua tarefa múltiplos desafios, entre eles o de construir no texto oral os aspectos visuais inerentes à língua de sinais. A pesquisa pretende oferecer uma amostra de como um público não fluente em língua de sinais, mas em processo formativo de tradução e interpretação, pode se relacionar com a performance artística e a interpretação simultânea. A investigação mostrou que a maioria dos alunos se sentem mais seguros com IS completa (com mais informações linguísticas). Entretanto, reconheceram que informações semióticas não precisariam ser interpretadas de forma a descrever a sinalização, dessa forma, promovendo o que pretendemos chamar de interpretação simultânea artística (ISA) que seria preservar o contato do espectador com os elementos visuais do texto.
\end{abstract}

Palavras-chave: Interpretação simultânea artística. Literatura surda. Performance em língua de sinais.

Abstract: This article assesses what elements may be omitted from a simultaneous interpretation of sign language (SI) narratives for audiences which are not fluent in Brazilian Sign Language - LIBRAS. Stories in sign language are visual performances that constitute a complex network of linguistic and semiotic information, gestures and body language. This study considers the perceptions of student interpreters of two different simultaneous interpretations of a LIBRAS narrative, entitled "Signs on the subway". Interpretation-translation is an act of cultural mediation with multiple challenges, including building the visual aspects inherent in sign language into the voiced text. This research provides a sample of how a non-fluent audience in sign language, but familiar with the processes of translation / interpretation, can relate to the artistic performance and simultaneous interpretation. We find that most students felt confident with a full SI, but acknowledged that semiotic information would not need descriptive interpretation. This latter approach could promote a form of artistic simultaneous interpretation (ASI) that keeps the audience in touch with the visual elements of the text.

Keywords: Artistic Simultaneous Interpretation. Deaf literature. Performance in sign language. 


\section{Introdução}

$\mathrm{N}$

a comunidade surda contar histórias em língua de sinais tornou-se uma marca cultural (STROBEL, 2008), pois é através das histórias que um povo produz e reproduz suas memórias. Essas histórias e memórias são repassadas por gerações, que contam suas lutas, suas angústias, seu humor, o jeito surdo de ver e vivenciar o mundo (PERLIN e MIRANDA, 2003). A divulgação dessas histórias tem sido muito importante para a comunidade surda, que tem se conhecido e se dado a conhecer. Considerando que a comunidade surda é também constituída por pessoas ouvintes e que muitos surdos nascem em famílias ouvintes, torna-se natural o movimento de muitos ouvintes em direção à cultura surda. $\mathrm{O}$ contato do ouvinte com os surdos é muitas vezes atravessado pela tradução/interpretação em diferentes contextos ${ }^{2}$. A forma como a tradução/interpretação é feita, poderá influenciar no quanto e como o ouvinte acessará do surdo. Pretendemos considerar o quanto a Interpretação Simultânea Artística ${ }^{3}$ (ISA) poderá contribuir na disseminação da cultura surda para cultura ouvinte. De que forma um público que não é fluente em língua de sinais consegue se relacionar com uma performance artística ${ }^{4}$ e com a interpretação simultânea nesse contexto ${ }^{5}$.

34 Temos a intenção de promover a ISA como uma modalidade de IS $^{6}$ onde o público alvo é agente ativo nesse processo. Que a interpretação do texto performático em língua de sinais seja de responsabilidade de todos os envolvidos (artista surdo, intérprete e público alvo). A situação de uma apresentação ao vivo envolve o contato do artista com seu público, esse contato pode ser direto ou não, dependendo da postura do artista. Geralmente os artistas surdos preferem que suas apresentações não sejam interpretadas para a língua oral, desejam ter um contato direto com seu público ouvinte, que sua arte seja vista e não ouvida (SUTTON-SPENCE E QUADROS, 2013). Naturalmente compreendem a necessidade de interpretação quando sabem que os espectadores não dominam a língua de sinais. Mesmo em casos onde sem interpretação dificilmente o texto será compreendido, muitos optam pela não interpretação assumindo essa postura para o público. Outros entendem que alguns sinais devem ser interpretados, o Tradutor e Intérprete de Língua de sinais (TILS) fornece a interpretação de alguns sinais que serão usados e que serão chaves para a compreensão da história, do poema. Dessa maneira, o espectador poderá deter-se mais sobre os aspectos visuais da língua de sinais. Sutton-Spence e Quadros (2013), afirmam que uma tradução ${ }^{7}$ completa do poema pode ser bela, mas poderia distrair os espectadores da performance em si. Oferecer palavras, como dicas complementa para compreensão do poema sem sobrepô-lo. 
A literatura surda é uma manifestação artística que usa a língua de sinais em sua potencialidade visual como matéria-prima, extraindo dela seus múltiplos significados ou usando-a como instrumento para expressar a realidade. Dessa forma compreendemos elementos que são peculiares (uso de classificadores CL, ênfase em expressões faciais EF e corporais, gestos) à construção de uma língua de sinais no contexto artístico, independente do tema apresentado. Propormos que o TILS deverá reconhecer essas características e apresentar uma interpretação simultânea no contexto artístico, que viabilize a manifestação cultural/artística da língua fonte na língua alvo. O TILS torna-se aliado do artista surdo no empoderamento linguístico e cultural, dando-lhe voz sem sobrepor sua sinalização (FELÍCIO, 2013, p.45). O trabalho de ISA visa colaborar na difusão da literatura surda. O TILS desenvolve um papel de agente cultural $^{8}$ quando elabora um texto na língua de chegada que pretende preservar, na medida do possível, os aspectos culturais da língua de partida. Torna-se um compromisso não somente com o surdo, mas com a cultura surda ${ }^{9}$. A investigação sobre a interpretação simultânea de contos pretende apresentar o quanto a literatura surda é atravessada pela tradução e interpretação. O desejo em fazê-lo é de perceber o quanto foi possível acessar a Libras e a cultura surda, pelos meandros do português, na interpretação simultânea.

O conto apresentado para este artigo foi criação de um surdo chamado Bruno Abraão e recontado pela poetisa surda Fernanda de Araújo Machado ${ }^{10}$. Porém, não é somente o fato de a história ter sido criada por um surdo que a confere o status de literatura surda, mas é o enredo que também faz essa identificação. Podemos dizer que o conto "Sinais no metrô" ${ }^{11}$ é um ótimo exemplo de literatura surda por se tratar de criação de um surdo e sua perspectiva, com enredo envolvido pela cultura surda. O conto faz referência aos problemas de comunicação, a relação conflituosa entre surdos e ouvintes e a busca por harmonia ou consenso nessas relações, temas estes também tratados por (WILCOX, 2005). O conto borda questões como: a presença do TILS na vida do surdo, os ouvintes aprendendo Libras (Língua Brasileira de Sinais) com vistas a se comunicarem com os surdos, da visão de que a língua de sinais denuncia que a pessoa é surda e se não há conhecimento cultural são vistas como deficientes. Além de apresentar peculiaridades na performance surda que são marcas culturais, os aspectos visuais da língua na descrição dos personagens, as descrições imagéticas, as expressões não manuais, os classificadores. Conforme Quadros e Sutton-Spence (2006) os elementos apresentados acima são formas que distinguem uma obra de literatura produzida como arte. 
"Sinais no metrô" foi apresentado (em Libras e com IS para português) em um evento em homenagem ao dia do surdo ${ }^{12}$, o sarau de histórias contou com uma plateia bastante heterogênea de conhecedores de Libras, de pessoas que nunca viram um surdo ao vivo tão pouco a língua de sinais, de surdos e ouvintes. Esse evento aconteceu na Barca dos $\operatorname{Livros}^{13}$, um lugar onde a cultura literária é apresentada em línguas orais, eles contam com programação de saraus de histórias, oficinas de contação de histórias, momentos de leituras de livros entre outras atividades. A língua de sinais adentrou esse espaço como algo até mesmo exótico para muitos que desconheciam a destreza literária da Libras e dos surdos. Até mesmo para aqueles que já vivenciavam a cultura surda, foram surpreendidos pela performance de conto e poesia. Foi um momento muito importante para a cultura surda, houve um encontro de diferenças que há muito foi vista com os olhos da deficiência, foi apresentada a eficiência da língua de sinais em manifestar sua arte, seu sentimento, sua emoção, sua mensagem. Sim, os surdos contam histórias, piadas, declamam poesias, com a propriedade estrutural que toda língua exige.

Por meio dessa escrita a comunidade surda transmite sua cultura. Através dos registros fica firmado o seu processo histórico, seu senso de humor, sua poesia, seu romance, para conhecimento de outras culturas. É celebrada a diferença e não mais enfatizada a falta de audição. Constroem-se identidades e representações surdas a partir da consolidação de marcadores culturais. (FELÍCIO, 2014, p.192).

A literatura surda tem suas características marcadas especialmente pela experiência visual do surdo e da língua de sinais. Mas, também se destaca em suas formas de apresentação na comunidade surda e pelo povo surdo ${ }^{14}$. Uma performance em língua de sinais poderá ser constituída por elementos que a traduzirão como literatura surda, uma manifestação cultural marcada pelas questões que são intrínsecas ao jeito surdo de atuar no mundo. Dessa forma, a identificação desses marcadores culturais ${ }^{15}$ sedimenta o que há de peculiar e legítimo na produção literária dos surdos e sobre os surdos. Considerando a modalidade espaço-visual, que expõe o corpo, um traço importante na produção da literatura, demanda a necessidade de se olhar para o todo, o que o corpo quer dizer. $\mathrm{O}$ artista surdo não se poupa nessa exposição para apresentar sua mensagem, sua história. Utiliza de ferramentas linguísticas e semióticas ${ }^{16}$ para, não somente comunicar, mas expressar seus mais profundos apelos em sua mais sensível criatividade.

Também ao que tange o trabalho de difusão cultural através de tradução e interpretação dessas performances, o TILS necessita transitar na comunidade surda para conhecer elementos que auxiliarão a fazer uma tradução ou interpretação que leve em consideração os aspectos culturais da língua de sinais. Um exemplo desse conhecimento é quando um TILS que está realizando 
um trabalho de IS com a seguinte situação hipotética: (descrição da cena em Libras) o personagem $\mathrm{X}$ quer chamar atenção do personagem $\mathrm{Y}$ e para isso precisa apagar e acender a luz várias vezes, ele faz o movimento $\mathrm{CL}^{17}$ de apagar e acender. $\mathrm{O}$ intérprete poderá opta por falar: "X apaga e acende a luz insistentemente". O texto fica claro, mas não traz o aspecto da cultura surda de utilizar a luz ao invés do som para chamar atenção. Ele poderá interpretar: " $\mathrm{X}$ quer chamar a atenção de Y". Para o espectador que está assistindo a performance o movimento em CL poderá ser suficiente para que relacionem com o aspecto cultural de como chamar atenção do surdo e de como o surdo faz para chamar atenção.

No conto "Sinais no metrô", como exemplo, foram identificados os seguintes marcadores culturais que geralmente estão presentes nas produções literárias em língua de sinais, conforme Felício (2013, p. 90):

1) Experiência visual (forma de entender o mundo);

2) Constituição do ser surdo (relação com ouvinte, por exemplo);

3) Como o surdo se constitui, se vê, se identifica (encontro com seus pares, por exemplo);

4) Tocar para estabelecer relação/comunicação;

5) Cortar o olhar, cortar a relação/comunicação, rompimento;

6) Composição visual;

7) Personagem surdo;

8) Incorporação de personagens;

9) O surdo torna-se receptivo quando ouvinte demonstra disposição em se comunicar em língua de sinais;

10) Caracteriza ouvinte aprendendo Libras;

11) Uso das tecnologias para comunicação;

12) Desapontamento com a diferença linguística;

13) Presença de intérprete. 
A experiência visual é um grande marcador cultural surdo. O contato com o olhar é extremamente marcante na comunicação, seja ela na língua oral ou sinalizada. Considerando a grande incidência de contato visual que a língua de sinais exige e proporciona, delineia-se um elemento forte de marcação de identidade surda, bem como a expressão de todo corpo para a efetivação da comunicação. Ao ouvinte é possível ter acesso a uma história sem precisar ter contato visual com o locutor - existem obviamente os contornos da voz que proporcionam a quem ouve toda a emoção ou qualquer sentimento que esta queira provocar, porém o contato visual torna-se mais pessoal, mais comprometedor. Os contadores de histórias em línguas de sinais, especialmente os nativos dessas línguas sinalizadas, dispõem de forma naturalizada de talentos cênicos para atuação na contação das histórias de forma artística (WILCOX, 2006 e BAHAN, 2006), prendendo seu público por meio de algo que pode ser seu Todo, que é seu próprio corpo. Quando um surdo conta uma história ele apresenta aspectos de sua identidade, independentemente do tema que ele está abordando. Conforme assinala a poetisa surda, autora da performance do conto "Sinais no Metrô":

\begin{abstract}
A língua de sinais é carregada de elementos pertinentes somente a ela, tem estética e estilo próprios e cada usuário apropria-se da língua de maneira diferente. Nesse sentido, a língua de sinais não é somente uma vocação, mas sim uma construção que acontece por meio das experiências, por isso existem pessoas que sinalizam de modo mais brando e suave, enquanto outras, de modo mais firme e vibrante. Mesmo sendo toda a sinalização uma forma de inspiração, nunca será reproduzida no mesmo estilo, pois a língua é dinâmica. (ARAUJO, 2013, p.60)
\end{abstract}

Buscaremos compreender quais elementos da IS em contexto artístico, são importantes objetivando preservar a experiência visual do conto em língua de sinais. A apreciação de uma performance artística exige um olhar atento ao corpo do artista, pois é lá que estará a mensagem principal do texto, do texto do artista e não da interpretação. Como tratamos de duas línguas de modalidades distintas (canal auditivo e canal visual) é comum ocorrer sobreposição, por isso suscitamos a necessidade em observar as diferenças, se existem, para uma ISA de modo a otimizar o contato do espectador com a língua fonte.

\title{
1. Procedimento metodológico
}

O presente estudo é de caráter exploratório, pretende-se constatar e entender alguns fenômenos que ocorrem na compreensão da interpretação simultânea de contos em língua de sinais. Temos uma abordagem qualitativa, já que os resultados da investigação mostram exemplos pontuais para o desenvolvimento da análise. 


\subsection{Participantes da pesquisa:}

Os participantes desse estudo foram onze alunos do curso técnico de tradução e interpretação do Instituto Federal de Santa Catarina (IFSC) - Campus Palhoça Bilíngue, módulo 2 (segunda fase) com conhecimento intermediário de Libras. Todos são ouvintes e fluentes em português, a maioria já atua como TILS (Tradutores e Intérpretes de Língua de Sinais) em escolas. Dois participantes são pais de filhos surdos e não atuam profissionalmente como TILS, entretanto são participantes ativos da comunidade surda realizando interpretações informais. Os participantes serão identificados por sigla AT (aluno tradução) e número de 01 a 11 . A escolha dessa amostra se justifica por considerar o nível de conhecimento em Libras importante para o resultado. São alunos que estão em processo formativo, com nível intermediário em Libras e bem familiarizados com a língua e o processo tradutório. São capazes de reconhecer problemas e refletir sobre possíveis soluções para tradução e interpretação.

\subsection{Material usado:}

Vídeo com duração de 18 minutos do conto "Sinais no Metrô"18, com performance em Libras de Fernanda de Araújo Machado que é Surda. O conto "Sinais no metrô" tem como enredo um romance entre uma moça surda chamada Márcia e um rapaz ouvinte chamado Mário. Eles se conhecem no metrô, porém por alguns meses ficam se comunicando virtualmente, o que não permite a Mário saber que ela é surda. Quando ele decide se aproximar para conversar pessoalmente no metrô, ele então descobre a surdez e se desespera por não saber se comunicar com ela. Por sua vez, Márcia fica decepcionada com a reação dele e passa a ignorá-lo. Mário, desanimado, é incentivado por sua professora de faculdade a aprender Libras. Ele se anima e procura o INES (Instituto Nacional de Educação de Surdos). Quando se sente seguro para iniciar uma conversa, procura Márcia no metrô e a surpreende ao cumprimentá-la em Libras. Assim é rompida a barreira de comunicação imposta pela língua e os dois iniciam um romance que resulta em uma cerimônia de casamento realizada no metrô onde se conheceram, tendo os passageiros como participantes da celebração.

\section{Método:}

O vídeo foi exposto aos alunos em dois encontros. No primeiro encontro eles assistiram a história em Libras com interpretação simultânea que preservou as informações semióticas, chamamos de versão I: com pouca informação linguística, não foram interpretados classificadores, marcações não manuais (expressão facial (EF), movimento de corpo (MC), gestos). No segundo encontro foi apresentada a versão II de interpretação simultânea na íntegra, 
da mesma história: descrição dos classificadores, marcações não manuais (expressão facial, movimento de corpo, gestos).

Os alunos assistiram e ouviram a versão I e responderam por escrito as seguintes questões:

1) Quem são os personagens da história?

2) Onde a história acontece?

3) O que você compreendeu da história? Organize um resumo.

4) O que ficou faltando para melhor compreensão?

5) O que você conseguiu apreender pela Libras e não pela interpretação?

No segundo encontro assistiram a versão II e responderam as seguintes questões:

6) O que mais você compreendeu da história?

7) Quais aspectos da Libras você percebeu com a interpretação simultânea?

8) Ficou melhor receber mais informações pela IS em português? Explique por quê?

9) O que você conseguiu apreender pela Libras e não pela interpretação?

10) Qual interpretação preferiu? Por quê?

11) Em sua opinião, o que o intérprete deve interpretar?

O procedimento com os alunos foi realizado em dois encontros, pois o vídeo é longo e a intenção era que o processo não fosse cansativo. Logo após assistirem a primeira apresentação, começaram a responder ao questionário com tempo hábil para as devidas reflexões. No segundo encontro, eles já estavam familiarizados com a história, por isso a segunda versão de interpretação continha mais informações. Para a primeira versão, a intenção era justamente perceber o quanto de informação linguística poderia ser dispensado e de que maneira isso colaboraria para compreensão do texto em Libras.

\section{O que os participantes concluíram das duas versões de interpretação simultânea.}

Com base na análise das respostas ao questionário, foi possível quantificar dados e qualificar o resultado. Dos onze alunos participantes da pesquisa, quatro (AT1, AT2, AT3 e AT4) tiveram preferência pela primeira versão de IS (com poucas informações linguísticas) e sete (AT5, AT6, 
AT7, AT8, AT9, AT10 e AT11) preferiram a segunda versão de IS (com mais informações linguísticas). Esse resultado não surpreendeu, considerando o nível intermediário em Libras e ainda por se tratar de um curso técnico de tradução e interpretação de cunho mais instrumental ${ }^{19}$. AT7 e outros participantes argumentaram que preferiram a segunda versão por conter mais detalhes, na primeira versão haviam compreendido somente o contexto.

Ainda que o resultado, para essa amostra, tenha apresentado uma preferência maior por IS com muitas informações linguísticas, todos os participantes resaltaram a importância dos classificadores e expressões faciais como elementos facilitadores para compreensão do texto em Libras. Referindo-se a primeira versão, AT4 diz o seguinte: "Em Libras as histórias sempre têm mais emoção, provoca a imaginação. E em muitos momentos as expressões são tão claras que qualquer leigo conseguiria entender". AT5 manifestou preferência pela primeira versão, entretanto afirma que CL e EF são recursos que ajudam na compreensão: “Consegui compreender pouco, mas o que me facilitou foram as expressões faciais, expressão corporal e classificadores". AT3: "Movimento de corpo e expressão facial foram importantes para eu conseguir identificar a mudança de personagens". Tais respostas indicam para tradução e interpretação de performances, o quanto é relevante observar essas marcas no texto artístico (elementos que não estão presentes na literatura escrita ou falada ${ }^{20}$, que se distinguem de outros tipos de textos. Ainda revelam para o artista surdo o quanto esses elementos podem tornar sua performance mais acessível ao público que não conhece língua de sinais.

A pesquisa constata também que a maior preferência pela segunda versão de IS é atribuída a insegurança com a língua, como afirma AT10 em resposta a pergunta 9: "Prefiro em português, pois é minha língua materna” e AT11: "Sem dúvida, ficou facilitada a compreensão ao receber informações mais detalhadas em português, talvez por conter a língua materna a simplificação de processos mentais". Os entrevistados ainda consideram mais prudente que tudo seja descritivamente interpretado para garantir a compreensão integral do texto. Preferem não se aventurarem por uma interpretação mais subjetiva, intuitiva, pois quando um TILS deixa de dar a voz em algumas sentenças do texto sinalizado ele pode ser considerado um mal intérprete, pode ser julgado como quem não entendeu o que o surdo quis dizer (FELÍCIO, 2013). E por vezes não é isso que acontece, o TILS compreende e decide por oferecer ao espectador que faça o mesmo, que faça sua interpretação.

Entretanto, essa é uma decisão muito difícil de tomar no momento de IS. O TILS deverá estar consciente nesses momentos de decisões estratégicas e não deverá subestimar a capacidade do público de alcançar o sentido do texto. Curiosamente AT7 diz que "o intérprete deve 
interpretar tudo o que conseguir, sem perder o foco, mas sem esquecer a cultura da língua fonte”. Vemos aí questões implicadas à formação de profissionais TILS, onde o intérprete tem a responsabilidade de extrair o último suspiro da palavra, mesmo que não seja o desejo do autor/artista performático. AT2 sugere que "O TILS deve tentar passar a história com detalhes para se tornar bem próximo do que o contador deseja para o público alvo”. O que o artista deseja como interpretação para o público e o que o público precisa, poderá ser combinado com o TILS, conforme Quadros e Sutton-Spence (2013, p. 225) em entrevista com três poetas surdos:

\begin{abstract}
Eles querem que seus espectadores vejam a poesia no corpo, não somente compreendendo o significado das palavras. Então, se o significado para identificar os sinais está nas palavras, isso seria aceitável, mas as palavras devem apenas complementar a performance poética - eles não podem substituir a performance visual.
\end{abstract}

O TILS não é o único responsável pelo texto na língua alvo, em uma situação de IS de performance artística é fundamental avaliar as necessidades do tripé artista surdo - público alvo - TILS. Conforme opinião de AT1 sobre a segunda versão: "Ficou confuso, as vezes eu não 42 sabia se o sinal que tinha visto foi algo que eu interpretei ou algo dito pela intérprete", "Preferi a primeira versão, foi objetiva, clara e não prejudicou a interpretação”. Interpretação de quem? Ou seja, ocorreu sobreposição de canais (auditivo e visual). Quem está assistindo também está fazendo interpretação ${ }^{21}$, quando há muita informação semiótica a IS descritiva atrapalha o alcance do texto na língua fonte e quem está assistindo fica passivo a IS ou confuso. Os participantes que apontaram preferência pela segunda versão, pontuaram positivamente o fato de não precisarem fazer muito esforço para compreender o texto. Como observado por AT11 "Por ser mais clara, a compreensão demandou menor esforço”, porém AT11 também observa que muita informação linguística prejudica o contato com a língua fonte: "Ficou mais clara a compreensão do assunto, mas se perdeu muito da narrativa pessoal da autora". (O aluno se refere a autora do conto "Sinais no Metrô").

É justamente esse aspecto que precisa ser levado em consideração, o quanto é mais importante se prender a IS ao passo que a performance visual tem sua mensagem em todo corpo do artista? “Quando a interpretação é marcada com uma maior riqueza de detalhes é normal prestar mais atenção ao intérprete, mesmo que se tenha domínio da segunda língua. A riqueza dos detalhes pessoais da narrativa (sentimentos, ênfase, utilização morfológica, metáforas, etc.) ficam em segundo plano, "achatando" a narrativa ao contexto da informação. Torna-se difícil 
(impossível) narrar a originalidade pessoal, pela própria singularidade trazida em cada pessoa”. (AT11)

Quando se tem a opção de IS o esforço em alcançar o sentido e a arte no texto performático fica quase nulo, o espectador poderá sentir-se mais seguro com IS, no entanto não está considerando o quanto poderá alcançar da cultura da língua fonte no corpo do artista surdo. Naturalmente a IS se faz muito necessária para espectadores que não conhecem Libras ou conhecem pouco. Entretanto, em se tratando de duas línguas com modalidades diferentes, a língua fonte espaçovisual e a alvo oral-auditiva, o espectador poderá fazer associações de informações linguísticas (prestadas pela IS) com as informações semióticas (CL, EF, MC), acessando a língua fonte sem maior intervenção do TILS.

"Quando ocorre uma interpretação tão detalhada o esforço em compreender a Libras se torna menor. Além disso, com tanta informação quase não dá tempo de prestar atenção na Libras". AT2

A ISA se justifica por consolidar os aspectos culturais da literatura surda na performance de contos, poesias, piadas. Quando os entrevistados pontuam que classificadores, expressões faciais, movimento de corpo, gestos, sinalizam sentimentos, emoções, ações que estão claramente representadas na performance, podemos dizer que a função do texto literário foi alcançada. Comunicou e entreteve. O público foi até o texto fonte com ajuda ou não da ISA, extraiu da cultura surda sem sobrepor ao canal visual o canal auditivo. AT3 diz sobre primeira versão: "Os classificadores mostraram detalhes descritivos que foram perceptíveis, mas omitidos na IS o que não alterou a compreensão do texto”. Em complemento, AT2 falando sobre a compreensão do texto em Libras: "A segunda versão foi mais detalhada, porém os detalhes que foram acrescentados não foram tão relevantes a ponto de alterar o resultado final da história”.

Em ambas das opiniões, interpretação de informações semióticas poderia ser dispensada, tornando a interpretação aliada estratégica do texto sinalizado. A ISA poderá se constituir por estratégias que resultará em um trabalho especializado. O TILS atuará consciente de seu papel mediador da língua, da arte e da cultura dessa língua. Por exemplo, as omissões que os entrevistados observaram foram positivas na preservação da informação visual. Deixando a IS com um texto mais leve, mais objetivo e a arte estava na performance e não no texto em português. A IS é artística não por apresentar um texto poético, eloquente, mas por permitir o contato direto entre espectador e artista surdo através das dicas de interpretação. AT11 "Na segunda versão ficou mais clara a compreensão do assunto, mas se perdeu muito da narrativa 
pessoal da autora [...] A expressão dos sentimentos ficou obnubilada pela tradução”. AT11 confirma que uma IS com muitas informações linguísticas afasta o público da performance. Ao passo que os entrevistados em sua maioria manifestaram preferência pela segunda versão de IS (com mais informações linguísticas), refletiram sobre essa forma de se fazer considerando o esforço, por vezes desnecessário, que o TILS faz para esse tipo de IS. AT2 apontou que: " $O$ TILS deve interpretar a intenção, deve reproduzir o máximo possível, mas deve programar essa interpretação para não correr o risco de se cansar no caminho e perder informações importantes no fim" e AT6 "interpretar de forma resumida para não haver desgaste do intérprete". A teoria do modelo dos esforços ${ }^{22}$ de Daniel Gile (1995) corrobora com as respostas dos entrevistados AT2 e AT6, porém não é nosso foco aqui aprofundá-lo. Cabe citar que Gile (1995) elaborou a teoria do modelo dos esforços a partir de suas investigações sobre a interpretação simultânea e afirma que é constituída por três componentes ou esforços principais: "componente de audição e análise, um componente de produção de discurso oral e um componente da memória de curto prazo" (Gile, 1995, p.162). Ou seja, o primeiro componente trata da capacidade do interprete em compreender o discurso que está sendo 44 proferido na língua fonte; o segundo componente compreende em o intérprete criar e gerar o discurso na língua alvo; o terceiro componente consiste na capacidade do intérprete em armazenar o que foi dito na, ao que Gile chama de, "memória de curto prazo".

Percebemos algumas inconstâncias, AT2 sugere interpretar a intenção, depois interpretar o máximo possível, mas deve cuidar para não se cansar e começar a omitir informações importantes. São questões atravessadas diretamente pela formação de TILS, da maneira como têm sido conduzidas as tarefas desse profissional e sua relação com a cultura surda. Ainda não está claro seu papel no contexto artístico, as competências que precisam desenvolver e até onde vai sua responsabilidade com o texto surdo. Traduzir a intenção do artista, omitir alguns CL e $\mathrm{EF}$, falar somente palavras chaves para compreensão do texto sinalizado, contextualizar a história ou poema, podem ser estratégias empregadas para ISA. AT3 colocou que "o TILS pode oferecer informações necessárias para compreensão do contexto". É importante perceber o quanto foi possível refletir sobre esse tipo de interpretação e iniciar a quebra de alguns paradigmas presentes no âmbito das línguas de sinais, como por exemplo, uma IS que precisa dar conta da integralidade do texto oral. Neste caso, não se trata de ser intraduzível, ilegível, trata-se de promover o contato do espectador com seu artista e sua cultura.

AT8 diz que "o TILS deve interpretar tudo o que for possivel para não perder a essência da tradução, quanto mais riqueza de detalhes melhor será a compreensão dos ouvintes". 
Entretanto, o que queremos para uma ISA? Acessar a cultura surda através de sua literatura, nas performances dos artistas surdos. Que a audiência absorva as informações por via visual, que tenha a oportunidade de usar a imaginação, a criatividade. Que o texto surdo possa também ser seu no momento em que faz o movimento de ir até o texto, interpretando-o conforme as percepções que tem. AT11 concorda para interpretação:

"Interpretar o contexto e a informação principal, deixando a linha de raciocínio mais fluída durante a interpretação. Caso seja necessário uma maior riqueza de detalhes para a compreensão, convém utilizá-la, mas tendo em conta que a forma poética ou mesmo pessoal do narrador sofrerá perdas”.

Já existe, por parte de alguns alunos de tradução e interpretação, a consciência de preservação cultural em ISA.

\section{Conclusão}

A presente investigação apresentou algumas reflexões para realização de ISA que preserve valores culturais impressos nas línguas de sinais. Os entrevistados reconhecem que a IS pode distrair o público da performance do artista, considerando como perda ficar preso ao texto oral em detrimento ao visual. Também foi unanime que classificadores, expressões faciais e corporais, movimento de corpo e gestos, facilitam o acesso ao texto de forma mais envolvente. Desse modo, denotando traços de texto da literatura surda, dispensando redundâncias e sobreposição com IS. Tal diferença no texto poderá conduzir o TILS à IS específica, ao que atenderá ao contexto artístico, performático. Buscando produzir um texto na língua oral que seja parceiro ao texto apresentado na língua visual. Para estudantes de tradução e interpretação em processo formativo, esse foi um passo na reflexão sobre seu papel para com a cultura surda. Perceberam que neste caso, menos poderá ser mais, que palavras podem obnubilar (como dito por AT11) a performance do artista surdo.

\section{REFERÊNCIAS BIBLIOGRÁFICAS}

ARAUJO, F. M. de. Simetria na Poética Visual na Língua de Sinais Brasileira. Florianópolis: Dissertação [Mestrado em Estudos da Tradução] - UFSC. 2013.

BAHAN, Benjamin. Face-to-face Tradition in the American Deaf Community.Dynamics of the Teller, the Tale and the Audience. In: H-Dirksen L. Bauman, Jennifer L. Nelson, and Heidi M. 
Rose. Signing the Body Poetic: Essays on American Sign Language Literature. UNIVERSIDADE OF CALIFORINIA PRESS, 2006.

FELICIO, M. D. O Surdo e a contação de histórias: análise da interpretação simultânea do conto "Sinais no metrô". Florianópolis: Dissertação [Mestrado em Estudos da Tradução] UFSC. 2013.

GILE, D. The Effort Models in Interpretation. In: Basic Concepts and Models for Interpreter and Translator Training. Amsterdam/Philadelphia: John Benjamins, 1995. p. 159190.

KRENTZ, Christopher 'The camera as printing press; How film has influenced ASL literature' in H-Dirksen Bauman, Jennifer Nelson \& Heidi Rose (eds.) Signing the Body Poetic (California: University of California Press), 2006

NAPIER, J.; MCKEE, R.; GOSWELL, D. Sign Language Interpreting: theory \& practice in Australia and New Zealand. Sydney: The Federation Press, 2006.

PAGURA, Reynaldo. A interpretação de conferências: interfaces com a tradução escrita e implicações para formação de intérpretes e tradutores. DELTA, São Paulo, V.19. spe, p. 209236, 2003.

PAVIS, P. Dicionário de teatro. [tradução: J. Guinsburg e Maria Lúcia Pereira] $3^{\text {a }}$ ed. São Paulo: Perspectiva, 2008.

QUADROS, Ronice M. de; SUTTON-SPENCE, Rachel. Poesia em sinais: traços da identidade surda. In: QUADROS, R. M. de (Org.). Estudos surdos I: série de pesquisas. Petrópolis: Arara Azul, 2006.

O tradutor e intérprete de língua brasileira de sinais e língua portuguesa. Brasília: Secretaria de Educação Especial; MEC, 2007.

SUTTON-SPENCE, Rachel; QUADROS, Ronice M. Performance poética em sinais: o que a audiência precisa para entender a poesia em sinais. Estudos em Língua de Sinais. v. 2. Florianópolis: Editora Insular. 2013.

WILCOX, S. Aprender a ver. Rio de Janeiro: Arara Azul, 2005.

WURM, Svenja (2010) 'Translation across modalities: The practice of translating written text into recorded signed language'. Unpublished Doctoral dissertation, Heriot-Watt University, Department of Languages and Intercultural Studies.

\footnotetext{
${ }^{1}$ Lattes Márcia Dilma Felício. Disponível em: http://lattes.cnpq.br/3147093871946523

${ }^{2}$ Conforme a Lei ${ }^{\circ} 10.098$ de 19 de dezembro de 2000, que trata da lei de acessibilidade, garante ao surdo acesso a informação e a comunicação com a presença de profissional tradutor/intérprete em diversos contextos sociais. Como por exemplo, no sistema educacional, na saúde, na política, em órgãos públicos e à cultura.

${ }^{3}$ É a interpretação simultânea para língua oral de contos, poesias, narrativas e piadas apresentadas em língua de sinais. O conceito de ISA está sendo desenvolvido na tese de doutorado intitulada: A Interpretação Simultânea Artística de Contos em Libras. UFSC, programa de Estudos da Tradução.

${ }^{4}$ Performance do artista surdo em língua de sinais para apresentação de poesias, contos, piadas, teatro.
} 
${ }^{5}$ Napier, et. al. (2006, p.102) consideram que o trabalho de interpretação de performances artísticas não é tão comum como o trabalho de interpretação realizado nos contextos educacionais, médicos e jurídicos, por exemplo. Para o contexto artístico o intérprete posiciona-se em um local menos expositivo de modo a permitir o foco do público espectador somente à apresentação artística. Isso acontece, por exemplo, em casos de peças teatrais produzidas por surdos onde o texto é sinalizado e a interpretação precisa ser para a língua falada.

${ }^{6}$ Pagura (2003, p.212) apresenta outras modalidades de interpretação. Normalmente encontramos tanto nas pesquisas sobre o assunto como em nomenclaturas de modalidades interpretativas, usadas por profissionais ou não, interpretação simultânea e interpretação consecutiva são as mais comuns. Entretanto o autor fala de interpretação intermitente ou "sentence-by-sentence", ou ainda "ping-pong". Esta modalidade, segundo o autor, não é comumente utilizada e tão pouco investigada por profissionais da área. A reflexão sobre os vários tipos de interpretação possíveis se faz necessária visando ampliar nosso campo de ação para a execução mais eficiente da tarefa de interpretação em contexto artístico, nos proporcionando flexibilidade para encontrar, descobrir em que modalidade nosso trabalho melhor se desenvolve.

${ }^{7}$ Quadros e Sutton-Spence (2013, p.208), apresentam considerações sobre tradução e interpretação: "De maneira geral, há uma compreensão quanto a existência de uma diferenciação entre tradução e interpretação (por exemplo, Salevsky 1982, cited in Wurm 2010). Tradução tem algumas das seguintes características: o texto é repetível, o texto alvo fica disponível ao tradutor; a criação do texto fonte e a criação do texto alvo acontecem independentemente; o tempo é irrestrito; o produtor do texto fonte e o produtor do texto alvo estão ausentes; normalmente, os textos fonte e alvo são escritos (em forma de registro físico ou digital). A interpretação, por outro lado, está sob a pressão do tempo e os produtores dos textos fonte e alvo são falados (ou sinalizados, não gravados). Wurm (2010), no entanto, tem mostrado que essa distinção, na realidade, não é tão clara e nem seria, talvez, necessário estabelecer essa dicotomia. Quando uma poesia sinalizada é acompanhada pela língua falada, nós vemos elementos tradicionalmente atribuídos tanto à tradução como à interpretação. Por exemplo, ambos os textos, fonte e alvo, podem ter sido preparados e são repetidos (característica da tradução), mas o produtor do texto fonte e o receptor do texto alvo estão presentes (característica da interpretação), disponível como texto completo, assim, enquanto os dois textos podem ter sido criados independentemente (característica da tradução), eles podem ter sido recriados em paralelo (característica da interpretação); e, apesar da preparação ser irrestrita (tradução), o tempo disponível para produzir o texto alvo está restringido pelo tempo do texto produzido na língua fonte (interpretação). Assim, é difícil determinar claramente se nós estamos propondo algum tipo de tradução ou de interpretação. Na comunidade surda, no entanto, as pessoas que trabalham com línguas de sinais e faladas, normalmente, utilizam o termo interpretação para identificar o que fazem. Além disso, interpretação nos estudos literários refere à explicação do significado de um poema, representado em uma outra língua. Os leitores precisam estar conscientes dessa ambiguidade do termo."

${ }^{8}$ Felício (2013) considera o TILS como aliado da pessoa surda no processo de empoderamento linguístico e cultural, aponta-se para a reflexão sobre o compartilhamento de poder, olhando cuidadosamente para o trabalho de tradução e interpretação dos discursos. Especialmente no que concerne às produções literárias de autores surdos, o papel do tradutor/intérprete e da tradução e interpretação como agente cultural, o que possibilita a essa língua e cultura ter visibilidade, considerando os "poderes" da tradução que com frequência é vista como suspeita, pois domestica textos e neles inscreve valores linguísticos e culturais. O TILS ainda atua diretamente na desconstrução da patologia da surdez e do surdo como deficiente. Enfatiza-se que o TILS não denota deficiência e sim a diferença linguística e cultural da pessoa surda.

9 Karin Strobel no livro “As Imagens do outro sobre a Cultura Surda” (2008, p.24) define cultura surda: "É o jeito surdo de entender o mundo e de modificá-lo a fim de torná-lo acessível e habitável ajustando-os com as suas percepções visuais, que contribuem para a definição das identidades surdas e das "almas" das comunidades surdas. Isto significa que abrange a língua, as ideias, as crenças, os costumes e os hábitos de povo surdo”.

${ }^{10}$ Mestre em Tradução pela Universidade Federal de Santa Catarina (UFSC); graduada em Letras-Libras (UFSC) e em Educação Artística (UFRJ); artista plástica e poetisa surda.

${ }^{11}$ Conto que foi objeto de investigação de minha dissertação de mestrado, defendida e aprovada em 2013. O Surdo e a Contação de Histórias - Análise da Interpretação Simultânea do Conto "Sinais no Metrô". PGET - UFSC.

${ }^{12}$ No dia 26 de setembro, a Comunidade Surda Brasileira comemora o Dia Nacional do Surdo, data em que são relembradas as lutas históricas por melhores condições de vida, trabalho, educação, saúde, dignidade e cidadania.

${ }^{13}$ A Barca dos Livros - Porto de Leituras é uma biblioteca comunitária, mantida pela Sociedade Amantes da Leitura, com sede na Lagoa da Conceição, em Florianópolis, que defende a importância da leitura para o desenvolvimento comunitário e individual.

${ }^{14}$ Karin Strobel no livro "As Imagens do outro sobre a Cultura Surda", nos esclarece as diferenças entre comunidade surda e povo surdo. A autora aponta como definição de povo surdo (p. 31), que são sujeitos surdos que não habitam no mesmo local, mas que estão ligados por uma origem, por um código ético de formação visual, como as línguas de sinais, a cultura surda, uma forma semelhante de experimentar o mundo e quaisquer outros laços que os identifiquem. 
${ }^{15}$ Os marcadores culturais se referem às especificidades vivenciadas por surdos. Como abordado por Perlin, "marcadores" no sentido de que são formas "surdas" de experienciar o mundo.

${ }^{16}$ Quadros e Sutton-Spence (2013, p. 212) apresentam informações linguísticas como vocabulário da língua de sinais (sinais icônicos e arbitrários). Informações semióticas, segundo as autoras, seriam gestos, mímicas, expressões faciais, movimento de corpo.

${ }^{17}$ Em Libras os classificadores descritivos “desempenham uma função descritiva, podendo detalhar som, tamanho, textura, paladar, tato, cheiro, formas em geral de objetos inanimados e seres animados" (PIMENTA; QUADROS, 2006). Dessa forma os classificadores descrevem objetos, pessoas, animais, indicando movimentação e localização. Tornam-se uma forte característica das línguas de sinais, marcando culturalmente a visualidade. Sugerem uma representação de clara de como a língua de sinais se dá na construção do pensamento, por imagens. ${ }^{17}$ Consideramos instrumental, o curso técnico de tradução e interpretação Libras/Português do IFSC, por ser organizado de modo a priorizar mais a prática. É um curso que oferece em sua carga horária disciplinas que visam instrumentar o aluno para atuar profissionalmente, dessa forma, o recurso didático predominante é o de fazer traduções e interpretações avaliando o produto final e não o processo. Os alunos não estudam aprofundadamente as teorias de tradução e interpretação para embasar suas práticas e é muito comum encontrar alunos que fazem o curso somente para aprender Libras.

${ }^{18}$ O vídeo com o conto "Sinais no Metrô" não está publicado, consta no DVD do evento Barca dos Livros no acervo do IFSC - Campus Palhoça Bilíngue e arquivo particular do autor.

20 Sutton-Spence e Michiko Kaneko, no livro Introducing Sign Language Literature - Creativity and Folklore (no prelo), no capítulo What sign language literature has that spoken language literature has not, apresentam elementos referentes a língua de modalidade espaço-visual que marcariam diferenças para a literatura surda. Como por exemplo: velocidade; espaço; configurações de mão (estética); perspectivas múltiplas; antropomorfismo (incorporação de humanos, objetos, animais), classificadores; configurações de mão para metáfora e jogos com o alfabeto manual.

$48{ }^{21}$ De acordo com Pavis (2008, p. 212) interpretação no campo do teatro refere-se a uma "abordagem crítica do leitor ou pelo espectador do texto e da cena, a interpretação se preocupa em determinar o sentido e a significação. Ela concerne tanto ao processo de produção do espetáculo pelos 'autores' quanto ao de sua recepção pelo público". ${ }^{22}$ Ver mais em: GILE, D. The Effort Models in Interpretation. In: Basic Concepts and Models for Interpreter and Translator Training. Amsterdam/Philadelphia: John Benjamins, 1995. p. 159-190.

\section{RECEBIDO EM: 06 de julho de 2015 ACEITO EM: 01 de dezembro de 2015}

